\title{
Investigating the Optimal Time for Intrauterine Human Chorionic Gonadotropin Infusion in Order to Improve IVF Outcome: A Systematic Review and Meta-Analysis
}

\author{
MARA SIMOPOULOU ${ }^{*}$, KONSTANTINOS SFAKIANOUDIS $^{2 *}$, \\ EVANGELOS MAZIOTIS ${ }^{1}$, PETROULA TSIOULOU ${ }^{1}$, POLINA GIANNELOU $^{1,2}$, \\ SOKRATIS GRIGORIADIS ${ }^{1}$, AGNI PANTOU ${ }^{2}$, GEORGE ANIFANDIS ${ }^{3}$, \\ PANAGIOTIS CHRISTOPOULOS ${ }^{1}$, KONSTANTINOS PANTOS ${ }^{2 \#}$ and MICHAEL KOUTSILIERIS ${ }^{1 \#}$ \\ ${ }^{1}$ Department of Physiology, Medical School, National and Kapodistrian University of Athens, Athens, Greece; \\ ${ }^{2}$ Centre for Human Reproduction, Genesis Athens Clinic, Athens, Greece; \\ ${ }^{3}$ Department of Histology and Embryology, Faculty of Medicine, University of Thessaly, Larissa, Greece
}

\begin{abstract}
Background/Aim: Studies on the impact of intrauterine human Chorionic Gonadotropin (hCG) administration in order to improve the In Vitro Fertilization $(I V F)$ outcome have yielded conflicting results. The aim of the present systematic review and meta-analysis is to investigate whether timing of intrauterine $h C G$ administration prior to embryo transfer affects its efficiency. Materials and Methods: A systematic search of the literature on Pubmed/Medline, Embase and Cochrane databases was performed. Only Randomized Control Trials were included in this metaanalysis. Results: Live birth rates were not improved following $h C G$ administration $(R R=1.13,95 \% C I=0.88-1.46$, $p=0.34)$ in the pooled results. Combined live birth and ongoing pregnancy rates were borderline statistically significant following $h C G$ administration $(R R=1.27$, 95\%CI=1.00-1.62, $p=0.05)$. Following subgroup analysis regarding live birth and ongoing pregnancy rates, only the 512 minutes prior to the embryo transfer group reported a statistically significant improvement. Conclusion: Intrauterine infusion of $h C G$ within an IVF-Intracytoplasmic Sperm
\end{abstract}

This article is freely accessible online.

*Joint first co-authorship. "Joint last co-authorship.

Correspondence to: Mara Simopoulou, Department of Physiology, Medical School, National and Kapodistrian University of Athens, 75 Mikras Asias 11527, Athens, Greece. Tel: +30 2107462592, Fax: +30 2107462571, e-mail: marasimopoulou@hotmail.com

Key Words: Human chorionic gonadotropin, in vitro fertilization, live birth, meta-analysis, review.
Injection (ICSI) cycle improves outcome only when administered 5-12 min prior to embryo transfer.

The success rate of in vitro fertilization (IVF) has been reported to be at $29.1 \%$ on the first cycle when considered irrespectively of age and infertility etiology (1). Despite its 40 years of practice, numerous conundrums still remain to be delineated in an effort to identify a foolproof approach towards achieving a clinical pregnancy. Implantation of an embryo into the endometrial cavity depicts the product of a constructive, complex, molecular dialog between the embryo and the endometrium (2). Thus, a potential implantation failure may originate from the equal contribution of embryonic, endometrial and maternal parameters (3). Clinicians are often called to identify which parameter is the culprit of a failed implantation. In practice, it may often be unrealistic to reveal the true origin of the failure, which would enable the design of a future treatment accordingly. The process of implantation is still considered to be a "black box" in the IVF treatment, while years of efforts have focused on how to understand it and subsequently enhance implantation rates. The key-molecule that intervenes and principally controls the implantation procedure, in line with the subsequent pregnancy that it entails, is the human chorionic gonadotropin (hCG) (4).

HCG is an heterodimeric hormone, secreted by the blastocyst prior to implantation $(5,6)$. Its initial role appears to be the stimulation of progesterone production by the corpus luteum $(7,8)$. Thus, hCG's role shifts towards the maintenance of the upcoming pregnancy, principally through endorsing uterine angiogenesis, assuring maternal tolerance of the semi-allograft embryo, assisting uterine enlargement, which goes hand in hand with fetal development (5). 
Table I. Search strategy employed in all databases.

\begin{tabular}{ll}
\hline 1 & IVF \\
2 & In vitro fertilization \\
3 & ICSI \\
4 & Intracytoplasmic sperm injection \\
5 & Assisted reproduction \\
6 & ART \\
7 & MAR \\
8 & \#1 OR \#2 OR \#3 OR \#4 OR \#5 OR \#6 OR \#7 \\
9 & Cleavage stage embryo \\
10 & Morula \\
11 & Blastocyst \\
12 & Day 2 \\
13 & Day 3 \\
14 & Day 4 \\
15 & Day 5 \\
16 & Day 6 \\
17 & \#9 OR \#10 OR \#11 OR \#12 OR \#13 OR \#14 OR \#15 OR \#16 \\
18 & Embryo transfer \\
19 & \#17 AND \#18 \\
20 & Human chorionic gonadotropin \\
21 & hCG \\
22 & \#20 OR \#21 \\
23 & Intrauterine \\
24 & Infusion \\
25 & Administration \\
26 & \#24 OR \#25 \\
27 & \#23 AND \#26 \\
28 & \#22 AND \#27 \\
29 & \#8 AND \#19 AND \#28 \\
\hline &
\end{tabular}

In light of the fact that the main driver of research in the assisted reproduction field is to improve pregnancy rates, scientists have tackled that issue aiming to address questions such as: "How can we improve embryo culture conditions?", or "How can we achieve optimal receptivity of the endometrium?" It was not long before a hypothesis was formed questioning whether hCG administration via intrauterine infusion prior to the embryo transfer (ET) procedure may offer a noteworthy solution to implantation failure, resulting to superior pregnancy outcomes (9).

The novel approach of intrauterine hCG infusion was first brought up by Mansour and colleagues. The study concluded that $500 \mathrm{IU}$ of hCG in $1 \mathrm{~mL}$ of culture media mirrors the ideal concentration to be injected into the uterine cavity, about 7 minutes prior to ET, promising enhanced pregnancy rates (10). Hitherto, several prospective studies have advocated the benefit of hCG administration as a valid option for improvement of pregnancy rates during IVF/ICSI cycles $(6,11-13)$. In contrast, other studies have reported no positive effect of this approach with respect to pregnancy rates, and particularly for cases involving blastocyst ET $(14,15)$.

Further to the current discrepancies from reported results on efficiency, several studies have conducted intrauterine hCG

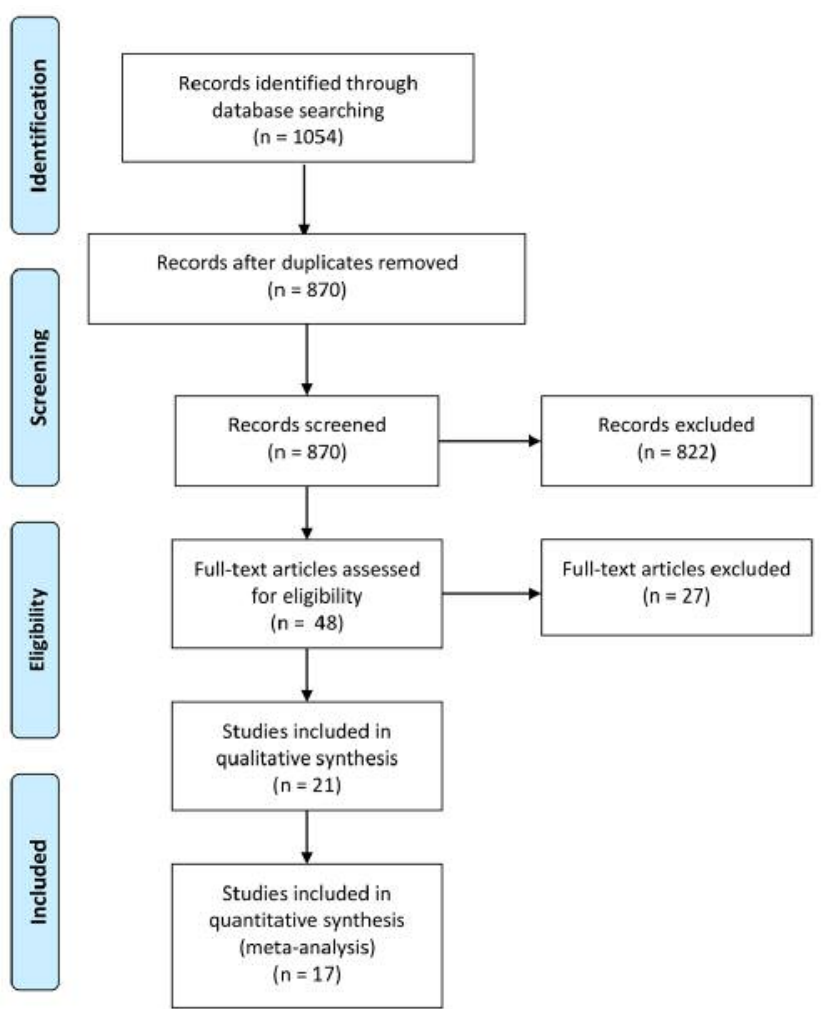

Figure 1. PRISMA flowchart regarding study selection.

administration using different protocols of infusion. These differences refer to the optimal concentration, and time points of administration, along with the employment/ or not of sonography. The scenario of conflicting studies concerning the benefits and drawbacks of novel approaches in IVF practice is well argued and documented in literature. Three meta-analyses have been conducted on the effect of intrauterine administration of hCG on the day of ET with conflicting results (16-18). The hitherto heterogeneous cohort of results, constitutes a dilemma for clinicians, and reflects the unmet need for a universal standardized protocol regarding the application of this innovative approach. It is this need, that renders this new metaanalysis timely and essential towards reaching a consensus regarding the true place of hCG administration on pregnancy and live-birth rates. Other contributions have been submitted on the matter of hCG administration, with a recent contribution assessing hCG administration efficiency from the point of view of the developmental stage of the embryos transferred (16). It is noteworthy, that the current study brings a different "angle" to the investigation, enriching the point of view regarding the optimal timing of hCG administration.

This metanalysis aims to address the need for designing a specific protocol on hCG administration. Besides, the ultimate 
Table II. Characteristics for studies included in this meta-analysis.

\begin{tabular}{|c|c|c|c|c|c|}
\hline Study & $\begin{array}{l}\text { Number of } \\
\text { participants }\end{array}$ & $\begin{array}{l}\text { Intervention group } \\
\text { Volume of Intrauterine } \\
\text { infusion of culture } \\
\text { media with hCG }\end{array}$ & Control group & $\begin{array}{l}\text { Dosage } \\
\text { (IU) }\end{array}$ & $\begin{array}{l}\text { Time point } \\
\text { Prior to ET }\end{array}$ \\
\hline Aaleyasin et al., 2015 & 483 & $50 \mu 1$ & Culture media ${ }^{a}$ & 500 & $5-7 \mathrm{~min}$ \\
\hline Cambiaghi et al., 2013 & 44 & Volume not specified & No placebo & 500 & $6 \mathrm{~h}$ \\
\hline Eskandar et al., 2016 & 240 & Volume not specified & No placebo & 500 & $10 \mathrm{~min}$ \\
\hline Firouzabadi et al., 2016 & 159 & $0.04 \mu \mathrm{l}$ & No placebo & 500 or 1000 & $7 \mathrm{~min}$ \\
\hline Hafezi et al., 2018 & 180 & $40 \mu \mathrm{l}$ & Culture mediaa \& no placebo & 500 & 7-10 min \\
\hline Hong et al., 2014 & 300 & $20 \mu 1$ & Culture mediaa & 500 & $<3 \mathrm{~min}$ \\
\hline Hosseini et al., 2016 & 100 & $40 \mu \mathrm{l}$ & No placebo & 500 & $7 \mathrm{~min}$ \\
\hline Huang et al., 2016 & 161 & $1 \mathrm{ml}$ & Saline \& no placebo & 1000 & 3 days \\
\hline Kokkali et al., 2014 ${ }^{\mathrm{b}}$ & 194 & Volume not specified & Culture media ${ }^{a}$ & 500 & $4 \mathrm{~min}$ \\
\hline Leao et al., 2013 & 36 & Volume not specified & No placebo & 500 & $6 \mathrm{~h}$ \\
\hline Mansour et al., 2011 & 212 & $40 \mu \mathrm{l}$ & Culture media ${ }^{a}$ & 500 & $7 \mathrm{~min}$ \\
\hline Mostajeran et al., 2017 & 100 & $5 \mathrm{ml}$ & No placebo & 700 & $5-10 \mathrm{~min}$ \\
\hline Navali et al., 2014 & 138 & $0.5 \mathrm{ml}$ & Saline & 500 & 3 days \\
\hline Santibañez et al., 2014 & 210 & $20 \mu l$ & Culture media ${ }^{a}$ & 500 & $4 \min$ \\
\hline Singh et al., 2014 & 216 & $40 \mu \mathrm{l}$ & Culture media ${ }^{a}$ & 500 & $5 \mathrm{~min}$ \\
\hline Wirleitner et al., $2015^{\mathrm{c}}$ & 1186 & $40 \mu \mathrm{l}$ & Culture media ${ }^{a}$ & 500 & 3 min or 2 days \\
\hline Zarei et al., 2014 & 182 & Volume Not specified & Unidentified volume of saline & $6500^{d}$ & $12 \mathrm{~min}$ \\
\hline
\end{tabular}

${ }^{a}$ Volume of the culture media infused for the control group was equal to the volume infused for the intervention group. ${ }^{\mathrm{b}}$ Both published and unpublished data are included following communication. ${ }^{~}$ Wirleitner study included two arms. In the first arm the administration was performed 3 minutes prior to ET, whereas in the other arm $\mathrm{hCG}$ administration was performed 2 days prior to ET. ${ }^{\mathrm{d}}$ The dosage corresponds to recombinant $\mathrm{hCG}$.

goal of a metanalysis is to conclude on an optimal practice and assist clinicians in decision making regarding the potential inclusion of a novel approach as a Standard Operation Procedure (SOP). The purpose of this study is to produce a systematic review and a meta-analysis that delineates and clarifies -for the first time- which is the optimal timing of hCG intrauterine infusion in order to adequately cement its application in clinical practice and efficiently assist the clinicians towards deciding on optimal practice.

\section{Materials and Methods}

Search strategy. A systematic search of the literature was performed in Pubmed/Medline, Embase and Cochrane Central databases on July 2018 (Table I). The keywords employed and combined for the search strategy were: "In Vitro Fertilization", "IVF", "Assisted Reproduction", "Assisted Reproduction Techniques", "Medical Assisted Reproduction", "Intracytoplasmic Sperm Injection", "ICSI", "human chorionic gonadotropin", "hCG", "Intrauterine Infusion", "Randomized control trial", "prospective study". The original search yielded 1054 studies from the three databases. Following the removal of duplicate studies $(n=184)$, all records were screened and full-text was sought and obtained for relevant articles. Relevant articles $(n=47)$, were identified following title and abstract screening, employing the flow chart of Preferred Reporting Items for Systematic Reviews and Meta-analysis (PRISMA) as presented in Figure 1. A total of 17 randomized controlled trials (RCTs) (6, $10-15,19-28)$ were employed in the present meta-analysis. Screening and selection of literature was performed independently by three authors. Citation mining was performed where the reference lists of all included articles and relevant reviews and metanalyses were reviewed to identify other articles of relevance. The search was limited to full-length manuscripts published in English in peer-reviewed journals up to July 2018. No protocol was submitted to the Prospero International Prospective Register of Systematic Reviews, providing details on conducting this study.

Excluded studies. The first arm of the study up to citation (10) was excluded as the low dosage levels were considered ineffective by the authors. The studies by Ye et al., 2015, Osman et al., 2016, Craciunas et al., 2016 (17, 18, 29) were not included in the quantitative synthesis as they were meta-analyses. The study by Janati et al., 2014 (30) was excluded as it was identical to (14), with the latter including more outcomes. The update of the study by Craciunas et al., 2016 was published in October 2018 (16), following the completion of the literature search performed for this metanalysis which was concluded in July 2018.

Study selection. Only RCTs were selected for the present study. The population included women undergoing IVF, while the intervention was defined as the administration of hCG prior to the ET procedure. The primary outcome measure was the live birth rate (LB). The secondary outcome measures were: i) biochemical pregnancy (BP), ii) clinical pregnancy $(\mathrm{CP})$, iii) live birth plus ongoing pregnancy $(\mathrm{LB}+\mathrm{OP})$, and iv) miscarriage rate. Ongoing pregnancy was coupled to live birth in a single measure, as performed in other metaanalyses $(31,32)$. It has been voiced that when performing RCTs on interventions regarding fertility/infertility, ongoing pregnancy is considered to be the desired outcome (33). Nonetheless, this point of view raises considerable controversy (34). 
Bias assessment. Assessment of bias was performed on the selected studies regarding: i) selection bias (randomization), ii) allocation concealment, iii) selective reporting, iv) blinding of patients and personnel, v) blinding of outcome assessment, vi) incomplete outcome data and vii) other possible sources of bias. The bias assessment was performed independently by three authors.

Statistical analysis. Data extraction was performed by three authors. Risk Ratio (RR) with 95\% Confidence Intervals (95\% CI) was employed for the analyses of the included studies. Either the fixedeffects or the random effects model was employed for pooling the results according to heterogeneity. Heterogeneity of the exposure effect was evaluated employing the $\mathrm{I}^{2}$ statistic. If the $\mathrm{I}^{2}$ value was $80 \%$ or greater, the meta-analysis was not performed due to high heterogeneity. If the $\mathrm{I}^{2}$ value was $60 \%$ or greater, indicating significant heterogeneity, the random effects model was employed. A chi-squared test for heterogeneity was also performed and the $p$ Values were presented. Funnel plots for a possible publication bias were performed. Sensitivity analysis was performed for the studies where culture media were administered as placebo in control groups. All statistical analyses were performed using the Review Manager (RevMan) software (built 5.3).

\section{Results}

Study characteristics. The evaluated characteristics for each study included in the present meta-analysis are presented in Table II. Characteristics include: i) number of participants, ii) intervention protocol, iii) dosage, and iv) time point of administration. In Table I, the "Intervention" column refers to the volume of intrauterine infusion of culture media enriched with hCG, while the "Control" column refers to the volume of the placebo (plain culture media or saline). In cases where the study proceeded straight to ET serving as a control group, this is indicated as "no placebo". Only one study employed recombinant hCG (28). Assessment of bias was performed and the results are presented in Figures 2 and 3. With regards to the subgroup analysis, all the studies that have described the timing of the intervention as "straight before the ET", report performing the infusion in less than 5 minutes prior to the ET procedure. Based on the above, the possible time frames for infusion for subgroup analysis were the following: i) "less than 5 minutes prior to ET" describing the "straight before the ET" group, ii) " 5 to 12 minutes prior to ET" describing the "minutes before the ET" group, where patients were asked to wait for a few minutes between the intervention and ET, iii) "hours prior to ET" and iv) "days prior to ET" describing the" hours and days prior to the ET" groups, respectively. There are no studies that report hCG administration between 12 minutes and 6 hours prior to ET.

Live birth rates. Six studies have reported results on LB rates $(10,15,19,22,24,27)$. Heterogeneity was statistically significant $\left(\mathrm{I}^{2}=79 \%, p<0.0001\right)$, thus the random effects model was employed. Pooled results failed to reveal any

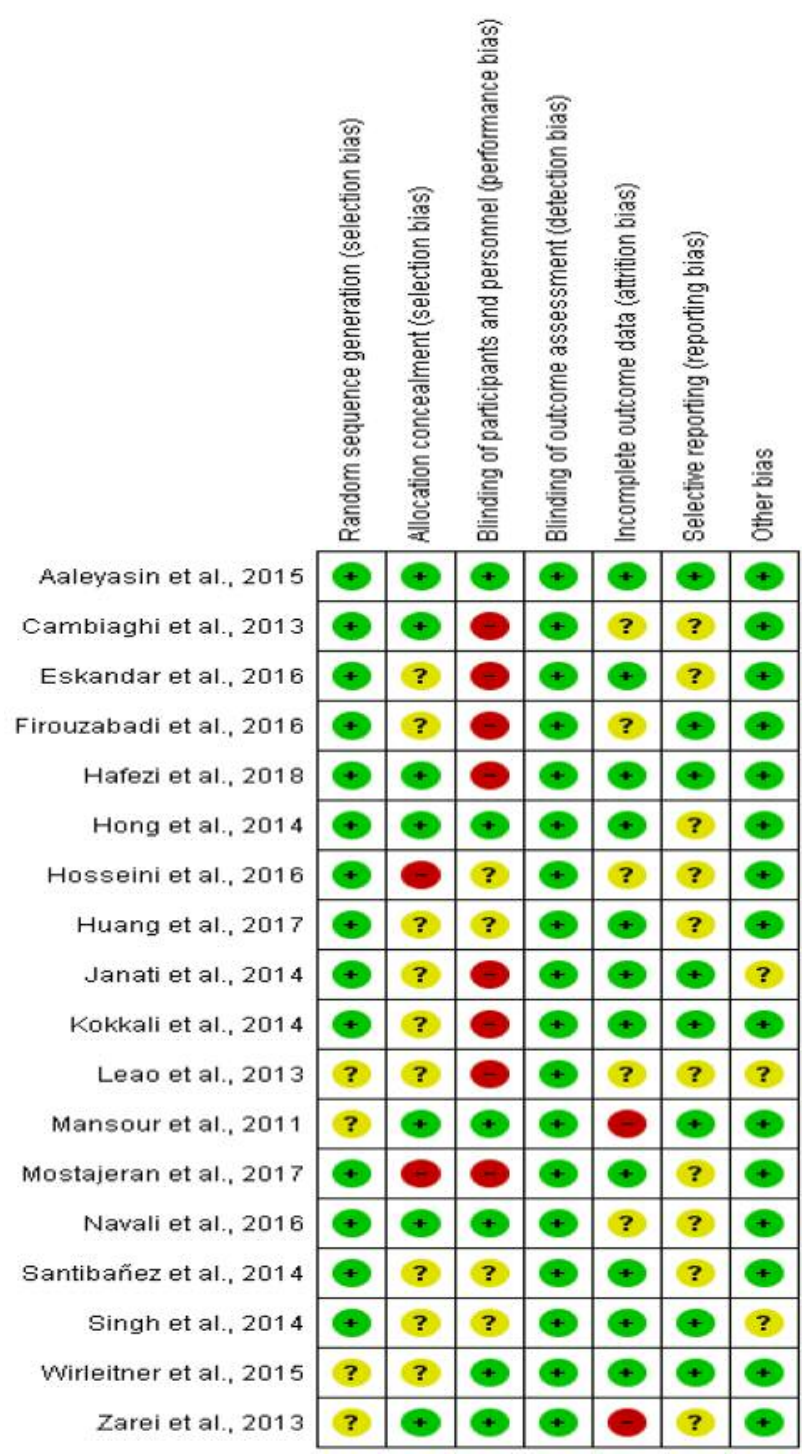

Figure 2. Assessment of bias for each study included. Green coding with positive sign represents low risk of bias, yellow coding with question mark represents unclear risk of bias, and red coding with negative sign represents high risk of bias.

statistically significant difference $(\mathrm{RR}=1.11,95 \% \mathrm{CI}=0.85$ $1.45, p=0.34)$. Performing a subgroup analysis for the group of studies in which hCG administration was performed $<5$ minutes prior to ET no statistically significant difference was observed $(\mathrm{RR}=0.81,95 \% \mathrm{CI}=0.57-1.15, p=0.24)$. Live birth rate was significantly higher following hCG administration 5 to 12 minutes prior to ET ( $\mathrm{RR}=1.42, \mathrm{CI}=1.10-1.84$, $p=0.007$ ). Only one study has reported on live birth rates following hCG administration days prior to ET (15) and no study has reported on live birth rates following hCG administration hours prior to ET (Figure 4). 


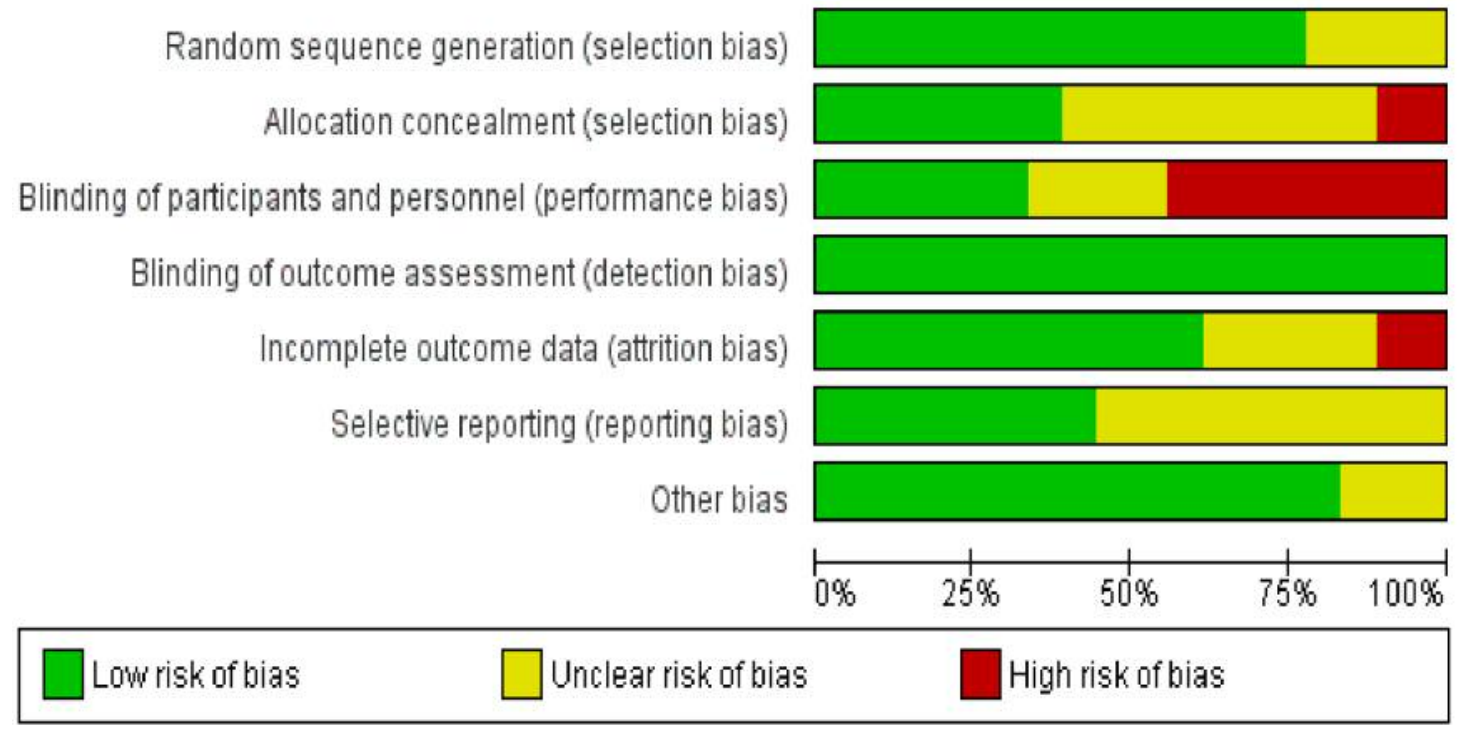

Figure 3. Review authors' judgements about each risk of biased item presented as percentages across all included studies.

Live birth/ongoing pregnancy rates. Six studies have reported results on $\mathrm{LB}$ rates $(10,15,19,22,24,27)$, and 3 studies have reported on ongoing pregnancy rates $(12,26,28)$. Heterogeneity was statistically significant $\left(\mathrm{I}^{2}=79 \%\right.$, $p<0.0001$ ), thus the random effects model was employed. Pooled results revealed a trend that marginally did not reach statistical significance $(\mathrm{RR}=1.27, \quad 95 \% \mathrm{CI}=1.00-1.62$, $p=0.05$ ), favoring hCG administration. Subgroup analysis did not reveal any statistically significant difference neither in the $<5$ minutes prior to ET group $(\mathrm{RR}=0.81,95 \% \mathrm{CI}=0.57$ $1.15, p=0.24)$ nor in the days prior to ET group $(\mathrm{RR}=1.52$, $\mathrm{CI}=0.87-2.66, p=0.14)$. The addition of the outcome of ongoing pregnancy strengthened the beneficial effect of $\mathrm{hCG}$ when administered 5-12 minutes prior to hCG $(\mathrm{RR}=1.47$, $\mathrm{CI}=1.19-1.83, p=0.0004$ ) (Figure 5).

Clinical pregnancy rates. Seventeen studies $(6,10-15,19$ 28) have reported results on clinical pregnancy rates. Heterogeneity was statistically significant $\left(\mathrm{I}^{2}=65 \%\right.$, $p<0.0001)$, thus the random effects model was employed. Pooled results revealed a statistically significant difference $(\mathrm{RR}=1.27,95 \% \mathrm{CI}=1.11-1.44, p=0.0005)$, favoring $\mathrm{hCG}$ administration. Subgroup analysis revealed a statistically significant difference only in the 5-12 minutes prior to ET group $(\mathrm{RR}=1.33, \mathrm{CI}=1.12-1.57, p=0.001)$. Statistically significant differences were not reported on neither of the other three groups, namely i) the $<5$ minutes prior to ET group $(\mathrm{RR}=1.11,95 \% \mathrm{CI}=0.92-1.35, p=0.28)$, ii) the hours prior to ET group $(\mathrm{RR}=1.12,95 \% \mathrm{CI}=0.76-1.65, p=0.56)$ and iii) the days prior to ET group $(\mathrm{RR}=1.52, \mathrm{CI}=0.86-2.69$, $p=0.15)$. It should be mentioned that heterogeneity in the days prior to ET group was very high, rendering the results of this particular subgroup lacking robustness $\left(\mathrm{I}^{2}=83 \%\right)$ (Figure 6).

Biochemical pregnancy rates. Eleven studies (6, 10, 14, 15, $19,20,22-24,26,28)$ have reported results on biochemical pregnancy rates. Heterogeneity was statistically significant $\left(\mathrm{I}^{2}=63 \%, p<0.002\right)$, thus the random effects model was employed. Pooled results revealed statistically a significant difference $(\mathrm{RR}=1.20,95 \% \mathrm{CI}=1.07-1.36, p=0.003)$, favoring hCG administration. Subgroup analysis revealed a statistically significant difference with respect to the 5-12 minutes prior to ET group $(\mathrm{RR}=1.21, \mathrm{CI}=1.06-1.38$, $p=0.006)$. Statistically significant differences were not revealed neither in the $<5$ minutes prior to ET group $(\mathrm{RR}=1.16,95 \% \mathrm{CI}=0.92-1.47, p=0.22)$, nor in the days prior to ET group $(\mathrm{RR}=1.34,95 \% \mathrm{CI}=0.70-2.56, p=0.15)$. It should be mentioned that heterogeneity in the days prior to ET group was significantly high, resulting in obscure results $\left(\mathrm{I}^{2}=85 \%\right)$. Only one study reported results in the hours prior to ET group thus analysis could not be performed (Figure 7).

Miscarriage rates. Ten studies (10, 12, 14, 15, 19, 22, 24, 26-28) have reported results on miscarriage rates. Heterogeneity was statistically insignificant $\left(\mathrm{I}^{2}=0 \%, p=0.82\right)$ thus the fixed effects model was employed. Pooled results did not reveal a statistically significant difference $(R R=1.10$, 95\% CI=0.83-1.45, $p=0.5$ ). Subgroup analysis also did not reveal any statistically significant difference neither in the 5- 


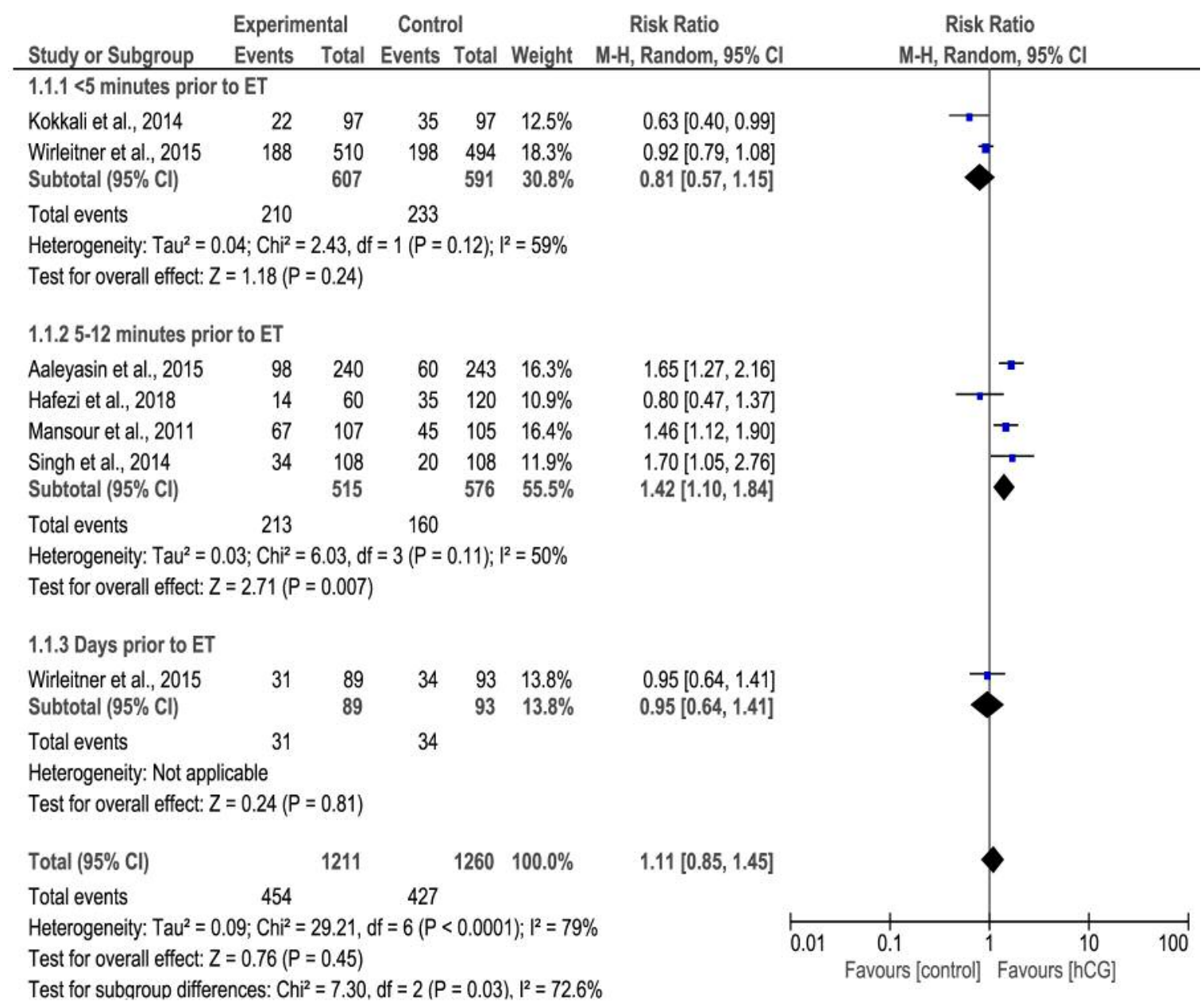

Figure 4. Risk ratio and Forest plot regarding live birth rates. df: degrees of freedom; Z: z-statistic.

12 minutes prior to ET group $(\mathrm{RR}=1.09, \mathrm{CI}=0.80-1.48$, $p=0.59)$ nor in the days prior to ET group ( $\mathrm{RR}=0.90$, $\mathrm{CI}=0.45-1.80, p=0.77)$. The $<5$ minutes prior to ET group also did not present with a statistically significant difference $(\mathrm{RR}=1.20,95 \% \mathrm{CI}=0.78-1.83, p=0.41)$, even though the heterogeneity was significantly high $\left(\mathrm{I}^{2}=86 \%\right)$ (Figure 8 ).

Sensitivity analysis. In the sensitivity analysis, only studies including culture media as placebo were employed $(11,12,15$, $19,22,27)$. Regarding the live birth rate outcome measure, excluding studies not employing culture media as placebo did not affect our results in a statistically significant fashion. Nonetheless, heterogeneity remained statistically very high $\left(\mathrm{RR}=1.25,95 \% \mathrm{CI}=0.90-1.72, p=0.18\right.$, four studies, $\mathrm{I}^{2}=78 \%$, $\mathrm{n}=2005)$. Subgroup analysis regarding the time of administration could not be performed as only the 5-12 minutes prior to ET subgroup was included in more than one studies (19, $22,27)$. When including the ongoing pregnancy rates, no statistically significant difference was reported $(\mathrm{RR}=1.22$, 95\%CI=0.94-1.60, $p=0.18$, five studies, $\mathrm{I}^{2}=72 \%, \mathrm{n}=2116$ ). Subgroup analysis revealed a statistically significant beneficial effect of hCG when administered 5-12 minutes prior to ET ( $\mathrm{RR}=1.64,95 \% \mathrm{CI}=1.31-2.05, p<0.0001$, three studies, $\mathrm{I}^{2}=0 \%$, $\mathrm{n}=819)$. It should be emphasized that all three studies are reporting on live birth rates. No statistically significant difference was observed in the days prior to ET group $\left(\mathrm{RR}=1.05,95 \% \mathrm{CI}=0.79-1.38\right.$, two studies, $\left.\mathrm{I}^{2}=0 \%, \mathrm{n}=293\right)$. Regarding the miscarriage rates outcome measure, the sensitivity analysis was performed in the same manner and did not affect our results in a statistically significant fashion ( $\mathrm{RR}=0.88, \mathrm{CI}=0.62-1.24, p=0.60$, five studies, $\left.\mathrm{I}^{2}=0 \%, \mathrm{n}=2116\right)$.

\section{Discussion}

In the last four decades, respectful efforts focus on improving IVF success rates via launching novel trends (35). These range 


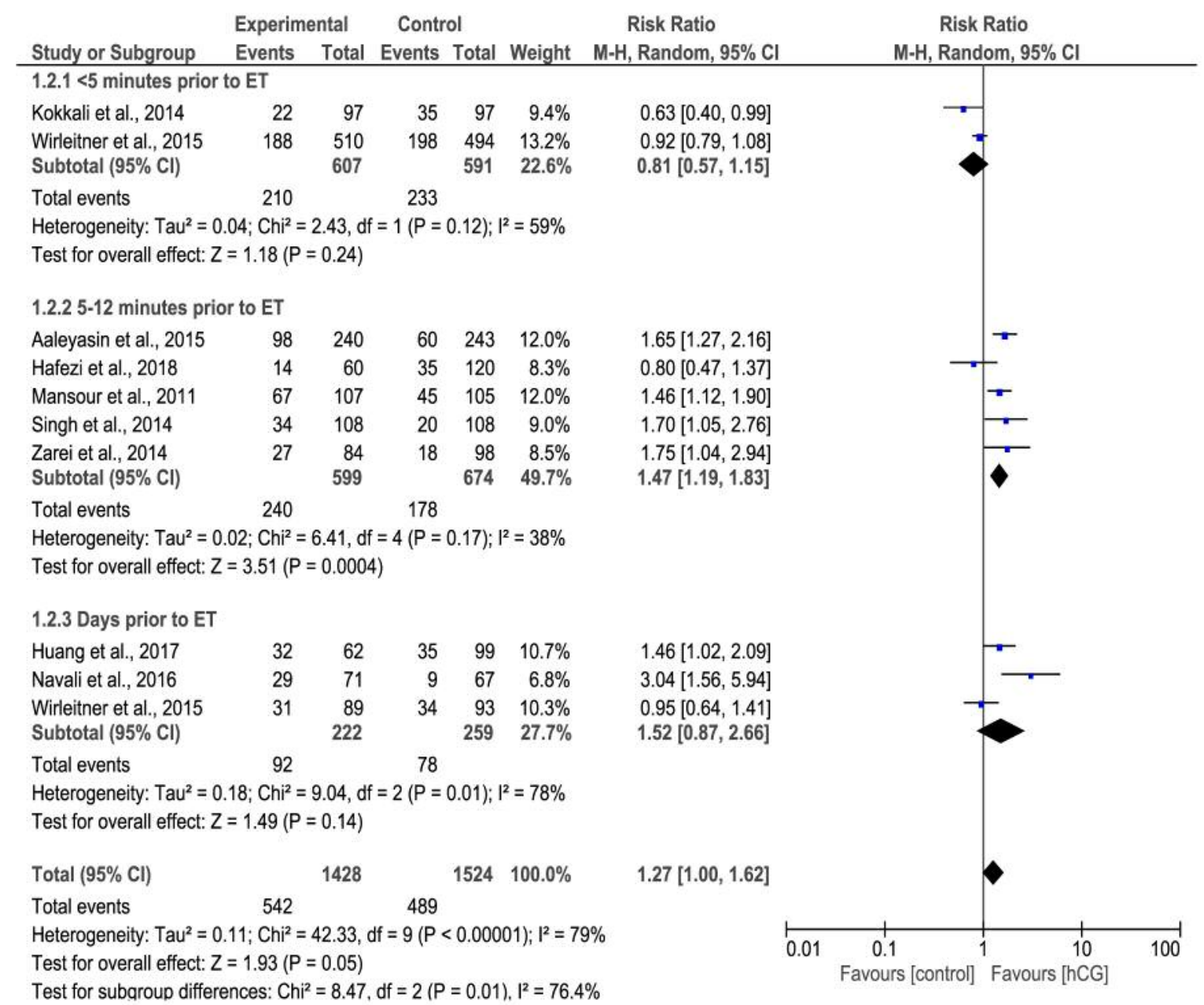

Figure 5. Risk ratio and forest plot regarding cumulative live birth and ongoing pregnancy rates.

from techniques employed to support the IVF laboratory performance, namely metabolomics for optimal embryo assessment and selection (36), to approaches regarding protocols in clinical practice. Emphasizing on improving implantation rates, the scientific community has brought to light a wide variety of innovative options in order to enhance the endometrial receptivity and contribute towards a successful implantation procedure. Studies have reported that: i) endometrial injury or scratching $(37)$, ii) the employment of stem cells $(38,39)$, iii) intrauterine platelet-rich plasma (PRP) infusion $(40,41)$, and iv) intrauterine hCG infusion prior to ET (17) could result in improving endometrial receptivity and implantation rates. The aforementioned options are highly promising, though still may be considered as ground-breaking and controversial, meriting further RCTs to cement their true role in optimal practice. Various perils could be associated with the employment of highly promising novel approaches. Hence, even if studies support the safety and effectiveness of clinical application, still the leap to adoption in clinical practice should be preceded by exhaustive trials. An example of this is the widely and routinely employed technique of Intracytoplasmic Sperm Injection (ICSI) that is still believed, by a part of the scientific community, to be the cause of epigenetic alterations (42). Research and development should involve studies on animal models, followed by in vitro tests on embryos that are donated for research, advancing to RCTs (43).

The scientific community has a responsibility towards accepting novel trends that leave conflicting impressions and are not part of established guidelines in clinical practice. The ideal scenario would be for the highly-esteemed Societies of Reproductive Medicine, to evaluate alternative trends and report on specific guidelines, regarding the clinical application of IVF. However, the accurate establishment of guidelines, accompanied by universally standardized 


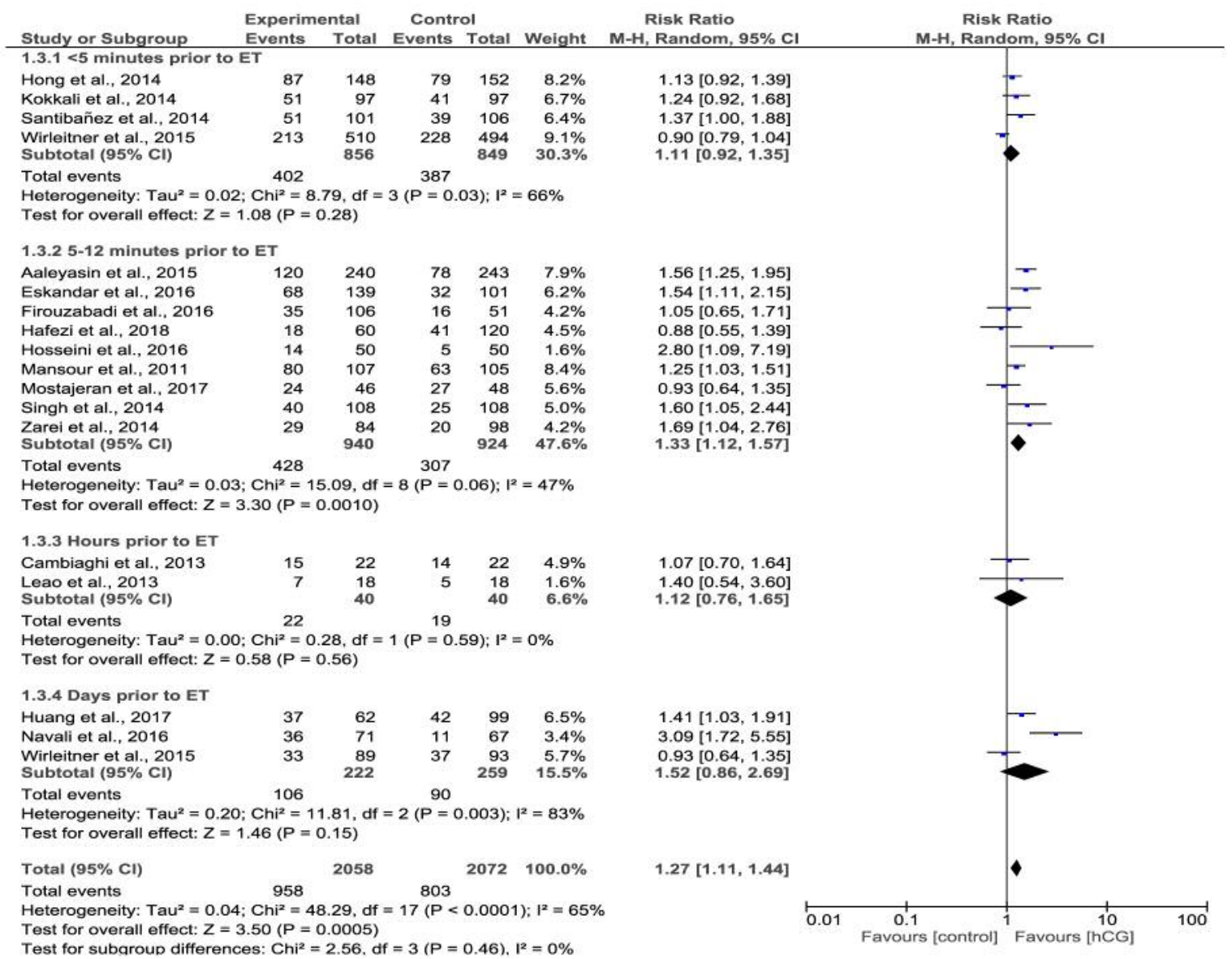

Figure 6. Risk ratio and Forest plot regarding clinical pregnancy rates.

protocols, is anticipated to require a considerable time. The final step prior to the admission of novel approaches in the clinical routine setting should be the completion of metaanalyses with favorable and cohesive results.

The process of implantation still remains as a conundrum in the physiology of reproduction. In the context of assisted reproduction, intrauterine infusion of hCG emerges as one of the promising trends in promoting successful implantation fueling this metanalysis. Different mechanisms have been described throughout the literature, regarding the underlying basis of hCG's fundamental function to adjust the process of the embryo's implantation. In 1998, results on delineating unknown mechanisms revealed the paracrine function of hCG influencing various growth factors and cytokines of paramount importance for the implantation window, such as the intrauterine insulin-like growth factor binding protein 1 (IGFBP-1), the macrophage colony-stimulating factor (MCSF), the leukemia inhibitory factor (LIF), the vascular endothelial growth factor (VEGF) and the matrix metallopeptidase 9 (MMP-9) (44). Other studies have indicated that hCG could stimulate the production of the transforming growth factor beta (TGF- $\beta$ ) or the receptor of interleukin- 1 . The growth factors and the cytokines secreted as a response to hCG are required in order to constitute the endometrium receptive towards the embryo (45). Last but not least, hCG has been documented to enable attraction of immune cells, namely neutrophils, monocytes and lymphocytes in vitro $(4,6,46)$.

The primary aim of this systematic review and metaanalysis study is to highlight the contradictions on the matter of hCG intrauterine infusion, and concur on its employment and effectiveness in clinical IVF routine. Our primary results indicate that hCG administration provides beneficial results regarding live birth rates only when administered 5-12 minutes prior to ET. As a secondary outcome, our results indicate that biochemical and clinical pregnancy rates, along with ongoing pregnancy and live birth rates, are also improved following hCG administration 5-12 minutes prior to ET. With respect to intrauterine hCG infusion and the 


\begin{tabular}{|c|c|c|c|c|c|c|c|c|}
\hline Study or Subgroup & \multicolumn{2}{|c|}{ Experimental } & \multicolumn{2}{|c|}{ Control } & Weight & $\begin{array}{l}\text { Risk Ratio } \\
\text { M-H, Random, } 95 \% \mathrm{Cl} \\
\end{array}$ & \multicolumn{2}{|c|}{$\begin{array}{l}\text { Risk Ratio } \\
\text { M-H, Random, } 95 \% \mathrm{Cl} \\
\end{array}$} \\
\hline \multicolumn{9}{|c|}{$1.4 .1<5$ minutes prior to ET } \\
\hline Kokkali et al., 2014 & 68 & 97 & 56 & 97 & $10.9 \%$ & $1.21[0.98,1.50]$ & & - \\
\hline Santibañez et al., 2014 & 53 & 101 & 39 & 109 & $8.3 \%$ & $1.47[1.07,2.00]$ & & \\
\hline $\begin{array}{l}\text { Wirleitner et al., } 2015 \\
\text { Subtotal }(95 \% \mathrm{Cl})\end{array}$ & 261 & $\begin{array}{l}510 \\
708\end{array}$ & 261 & $\begin{array}{l}494 \\
700\end{array}$ & $\begin{array}{l}13.6 \% \\
32.7 \%\end{array}$ & $\begin{array}{l}0.97[0.86,1.09] \\
1.16[0.92,1.47]\end{array}$ & & \\
\hline \multicolumn{9}{|c|}{$\begin{array}{l}\text { Heterogeneity: } \text { Tau }^{2}=0.03 ; \mathrm{Chi}^{2}=7.90, \mathrm{df}=2(P=0.02) ; \mathrm{I}^{2}=75 \% \\
\text { Test for overall effect: } Z=1.24(P=0.22)\end{array}$} \\
\hline \multicolumn{9}{|c|}{ 1.4.2 5-12 minutes prior to ET } \\
\hline Aaleyasin et al., 2015 & 131 & 240 & 87 & 243 & $11.2 \%$ & $1.52[1.24,1.87]$ & & - \\
\hline Firouzabadi et al., 2016 & 35 & 106 & 18 & 53 & $5.3 \%$ & $0.97[0.61,1.54]$ & & \\
\hline Hafezi et al., 2018 & 21 & 60 & 46 & 120 & $6.2 \%$ & $0.91[0.60,1.38]$ & & \\
\hline Hosseini et al., 2016 & 14 & 50 & 10 & 50 & $2.8 \%$ & $1.40[0.69,2.85]$ & & \\
\hline Mansour et al., 2011 & 84 & 107 & 65 & 105 & $11.9 \%$ & $1.27[1.06,1.52]$ & & $=$ \\
\hline $\begin{array}{l}\text { Zarei et al., } 2014 \\
\text { Subtotal }(95 \% \mathrm{Cl})\end{array}$ & 31 & $\begin{array}{r}84 \\
647\end{array}$ & 22 & $\begin{array}{r}98 \\
669\end{array}$ & $\begin{array}{r}5.4 \% \\
42.8 \%\end{array}$ & $\begin{array}{r}1.64[1.04,2.61] \\
1.29[1.09,1.53]\end{array}$ & & \\
\hline \multicolumn{9}{|c|}{$\begin{array}{l}\text { Heterogeneity: } \text { Tau }^{2}=0.01 ; \mathrm{Chi}^{2}=7.74, \mathrm{df}=5(P=0.17) ; \mathrm{I}^{2}=35 \% \\
\text { Test for overall effect: } Z=2.97(P=0.003)\end{array}$} \\
\hline \multicolumn{9}{|l|}{ 1.4.3 Hours prior to ET } \\
\hline $\begin{array}{l}\text { Cambiaghi et al., } 2013 \\
\text { Subtotal }(95 \% \mathrm{Cl})\end{array}$ & 19 & $\begin{array}{l}22 \\
22\end{array}$ & 18 & $\begin{array}{l}22 \\
22\end{array}$ & $\begin{array}{l}9.7 \% \\
9.7 \%\end{array}$ & $\begin{array}{l}1.06[0.82,1.37] \\
1.06[0.82,1.37]\end{array}$ & & \\
\hline \multicolumn{9}{|c|}{$\begin{array}{l}\text { Heterogeneity: Not applicable } \\
\text { Test for overall effect: } Z=0.41(P=0.68)\end{array}$} \\
\hline \multicolumn{9}{|l|}{ 1.4.4 Days prior to ET } \\
\hline Navali et al., 2016 & 42 & 71 & 21 & 67 & $6.3 \%$ & $1.89[1.26,2.83]$ & & \\
\hline $\begin{array}{l}\text { Wirleitner et al., } 2015 \\
\text { Subtotal }(95 \% \mathrm{CI})\end{array}$ & 42 & $\begin{array}{r}89 \\
160\end{array}$ & 45 & $\begin{array}{r}93 \\
160\end{array}$ & $\begin{array}{r}8.5 \% \\
14.8 \%\end{array}$ & $\begin{array}{l}0.98[0.72,1.32] \\
1.34[0.70,2.56]\end{array}$ & & \\
\hline \multicolumn{9}{|c|}{$\begin{array}{l}\text { Heterogeneity: } \text { Tau }^{2}=0.19 ; \mathrm{Chi}^{2}=6.62, \mathrm{df}=1(\mathrm{P}=0.01) ; \mathrm{I}^{2}=85 \% \\
\text { Test for overall effect: } Z=0.88(P=0.38)\end{array}$} \\
\hline Total $(95 \% \mathrm{Cl})$ & & 1537 & & 1551 & $100.0 \%$ & $1.22[1.07,1.39]$ & & 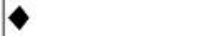 \\
\hline Total events & 801 & & 688 & & & & & \\
\hline $\begin{array}{l}\text { Heterogeneity: } \operatorname{Tau}^{2}=0 \\
\text { Test for overall effect: } Z\end{array}$ & $\begin{array}{l}3 ; \mathrm{Chi}^{2}=3 \\
2.89(\mathrm{P}=\end{array}$ & $\begin{array}{l}.80, \mathrm{df}= \\
.004)\end{array}$ & $=11(P=$ & $0.001)$ & $; 1^{2}=64 \%$ & & $\begin{array}{cccc}0.1 & 0.2 & 0.5 & 1 \\
& 0.1 & 1 \\
\text { Favours [control] }\end{array}$ & $\begin{array}{cccc} & 2 & 5 & 1 \\
\text { Favours }[\mathrm{hCG}]\end{array}$ \\
\hline
\end{tabular}

Figure 7. Risk ratio and forest plot regarding biochemical pregnancy rates.

possibility of associating it with miscarriage rates, no statistically significant difference was identified neither in the pooled results nor in any subgroup, extrapolating safety of the practice in that perspective. HCG administration performed during any other time frame did not convey any statistically significant improvement on live birth rates. When combining live birth rates with ongoing pregnancy rates no statistically significant difference was observed neither when hCG administration was performed in less than 5 minutes, or in the very opposite, days prior to ET. Biochemical and clinical pregnancy rates were not improved at any other point except during the 5-12-minute time frame prior to ET. With regards to limitations of our analysis, heterogeneity was very high regarding the clinical pregnancy rates in the 2-3 days prior to ET group, thus rendering the results of this subgroup less robust. Nonetheless, no statistically significant effect was observed in this subgroup regarding the ongoing pregnancy/live birth rates.
HCG is widely considered as the pregnancy hormone. The mRNA of hCG is firstly produced at the cleavage developmental stage of the embryo, and the mature mRNA at the blastocyst stage $(47,48)$. The cross-talk between the embryo and the endometrium may require the constant presence of hCG along with the respective effect it exerts, as it is proposed by a recent review (49). Therefore, it may be a safe hypothesis that the presence of hCG 5-12 minutes prior to the ET procedure may provide a beneficial effect on implantation potential contributing towards a successful pregnancy sustenance that results in a live birth.

The time frame 5-12 minutes prior to the ET appears to be optimal. Nonetheless, with regards to limitations, no study has reported hCG administration in the time frame defined as 13 minutes to $<6$ hours prior to ET, or in the time frame defined as $>6$ hours to $<2$ days. With regards to hCG administration at 6 hours and onwards, our results indicate that it may be ineffective. This may be attributed to the fact 
in vivo $33: 1737-1749(2019)$

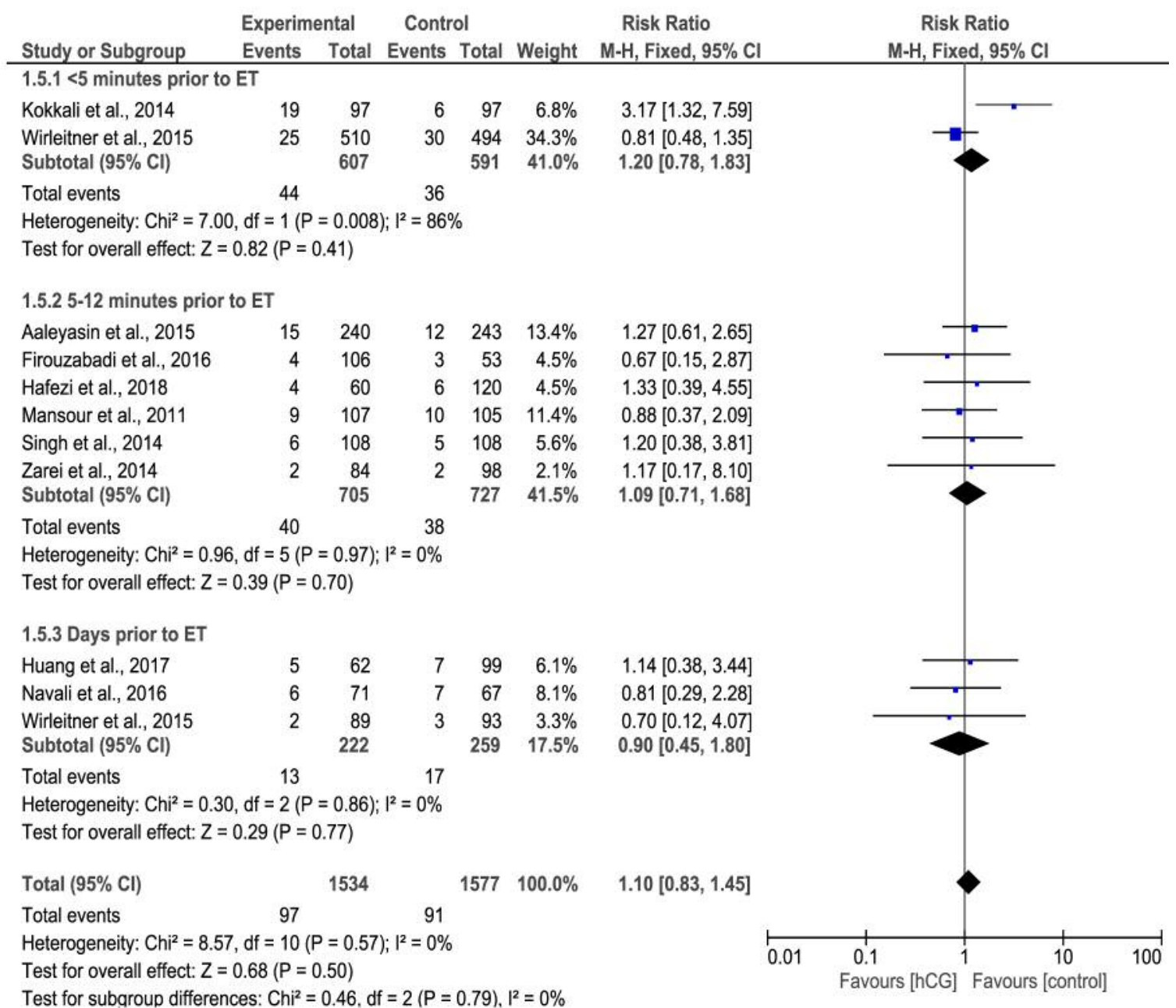

Figure 8. Risk ratio and forest plot regarding miscarriages rates.

that the half-life of exogenous hCG is 5-6 hours during the rapid phase (50). Further to that, the dosage of $500 \mathrm{IU}$ that was administered in this study may not be efficient to enhance clinical pregnancy and live-birth rates. On the other hand, trying to understand why hCG administration in less than 5 minutes prior to ET appears to be ineffective, one may hypothesize that the volume of fluid introduced in the uterine cavity so close to the ET procedure may contribute to increased volume following ET, and subsequent embryo "floating". Interestingly, embryo "floating" has been associated with a lower implantation potential (51). Moreover, the procedure of introducing a catheter prior to ET,similarly to the practice of mock ETs, may harbor perils depending on standards of practice. Previous studies have shown that low pregnancy rates may be associated with traumatic catheter introduction into the uterine cavity, as evident through direct visualization of endometrial lesions assessed immediately following catheter introduction (52). Thus, the possibility of causing minor trauma so close prior to the actual ET procedure may be involved in the lower rates corresponding to the hCG administration in less than 5 minutes prior to ET. Of course, such a hypothesis would stand independently as a confounder regarding any of the time frames. Nonetheless, no study has been conducted to assess the response of the endometrium with regards to the pathways activated during certain timeframes following minor injury.

The present meta-analysis may assist the clinicians in decision-making regarding the optimal time of hCG administration prior to ET. A seemingly simple time shift of hCG administration in the patients' schedule with respect to the ET procedure, could potentially exert a considerable 
effect on the clinical outcome and effectiveness of the IVF. Therefore, it is of pivotal importance to design and implement a specific ET SOP in cases where hCG infusion is included in the protocol. This may be of particular importance, especially in a highly demanding IVF laboratory setting. In addition to that, the results of the present metaanalysis could be considered in line with the recent metaanalysis of Craciunas and colleagues (16). It may be possible that the optimal practice includes hCG administration at minimum dosage of $500 \mathrm{IU}, 5$ to 12 minutes prior to the transfer of cleavage stage embryos. The current study highlights a significant improvement on ongoing pregnancy and live birth rates following intrauterine administration of hCG 5-12 minutes prior to ET. Further to that, the data sourced herein are reassuring with respect to miscarriage rates not being affected by this intervention.

\section{Conflicts of Interest}

The Authors declare that no conflicts of interest exist in regards to this study.

\section{Authors' Contributions}

MS contributed to conceiving and designing the review, drafting and editing of the manuscript and assessment of bias; KS contributed to conceiving and designing the review; EM in assessment of bias, data extraction and statistical analysis; PT in study selection, assessment of bias and data extraction; PG in study selection and drafting; AP in study selection and literature search; SG in statistical analysis and drafting of the manuscript; $\mathrm{PC}$ in literature search and manuscript drafting; GA in data extraction and editing of the manuscript; KP in study selection and editing of the manuscript; MK in reviewing and editing the manuscript.

\section{Acknowledgements}

No funding was sought or received for the present study.

\section{References}

1 McLernon DJ, Maheshwari A, Lee AJ and Bhattacharya S: Cumulative live birth rates after one or more complete cycles of IVF: a population-based study of linked cycle data from 178,898 women. Hum Reprod Oxf Engl 31: 572-581, 2016. PMID: 26783243. DOI: 10.1093/humrep/dev336

2 Benner M, Ferwerda G, Joosten I and van der Molen RG: How uterine microbiota might be responsible for a receptive, fertile endometrium. Hum Reprod Update 24: 393-415, 2018. PMID: 29668899. DOI: $10.1093 /$ humrep/dmy012

3 Coughlan C, Ledger W, Wang Q, Liu F, Demirol A, Gurgan T, Cutting R, Ong K, Sallam H and Li TC: Recurrent implantation failure: definition and management. Reprod Biomed Online 28: 1438, 2014. PMID: 24269084. DOI: 10.1016/j.rbmo.2013.08.011

4 Srivastava A, Sengupta J, Kriplani A, Roy KK and Ghosh D: Profiles of cytokines secreted by isolated human endometrial cells under the influence of chorionic gonadotropin during the window of embryo implantation. Reprod Biol Endocrinol 11: 116, 2013. PMID: 24269084. DOI: 10.1016/j.rbmo.2013.08.011

5 Choi J and Smitz J: Luteinizing hormone and human chorionic gonadotropin: Origins of difference. Mol Cell Endocrinol 383: 203213, 2014. PMID: 24365330. DOI: 10.1016/j.mce.2013.12.009

6 Santibañez Á, García J, Pashkova O, Colín O, Castellanos G, Sánchez AP and De la Jara JF: Effect of intrauterine injection of human chorionic gonadotropin before embryo transfer on clinical pregnancy rates from in vitrofertilisation cycles: a prospective study. Reprod Biol Endocrinol 12: 9, 2014. PMID: 24476536. DOI: $10.1186 / 1477-7827-12-9$

7 Cole LA: Biological functions of hCG and hCG-related molecules. Reprod Biol Endocrinol RBE 8: 102, 2010. PMID: 20735820. DOI: $10.1186 / 1477-7827-8-102$

8 Ezcurra D and Humaidan P: A review of luteinising hormone and human chorionic gonadotropin when used in assisted reproductive technology. Reprod Biol Endocrinol RBE 12, 2014. PMID: 25280580. DOI: 10.1186/1477-7827-12-95

9 Volovsky M, Healey M, MacLachlan VB and Vollenhoven BJ: Intrauterine human chorionic gonadotropin (HCG) infusion prior to embryo transfer (ET) may be detrimental to pregnancy rate. Fertil Steril 106: e52, 2016. PMID: 26783243. DOI: 10.1016/ j.fertnstert.2016.07.160

10 Mansour R, Tawab N, Kamal O, El-Faissal Y, Serour A, Aboulghar $M$ and Serour G: Intrauterine injection of human chorionic gonadotropin before embryo transfer significantly improves the implantation and pregnancy rates in in vitro fertilization/intracytoplasmic sperm injection: a prospective randomized study. Fertil Steril 96: 1370-1374.e1, 2011. PMID: 22047664. DOI: 10.1016/j.fertnstert.2011.09.044

11 Hong KH, Forman EJ, Werner MD, Upham KM, Gumeny CL, Winslow AD, Kim TJ and Scott RT: Endometrial infusion of human chorionic gonadotropin at the time of blastocyst embryo transfer does not impact clinical outcomes: a randomized, doubleblind, placebo-controlled trial. Fertil Steril 102: 1591-1595.e2, 2014. PMID: 25234040. DOI: 10.1016/j.fertnstert.2014.08.006

12 Huang P, Wei L and Li X: A study of intrauterine infusion of human chorionic gonadotropin (hCG) before frozen-thawed embryo transfer after two or more implantation failures. Gynecol Endocrinol 33: 67-69, 2017. PMID: 27449969. DOI: $10.1080 / 09513590.2016 .1207164$

13 Mostajeran F, Godazandeh F, Ahmadi SM, Movahedi M and Jabalamelian SA: Effect of intrauterine injection of human chorionic gonadotropin before embryo transfer on pregnancy rate: A prospective randomized study. J Res Med Sci 22, 2017. PMID: 28400828. DOI: 10.4103/1735-1995.199096

14 Firouzabadi RD, Janati S and Razi MH: The effect of intrauterine human chorionic gonadotropin injection before embryo transfer on the implantation and pregnancy rate in infertile patients: A randomized clinical trial. Int $\mathrm{J}$ Reprod Biomed 14: 657-664, 2016. PMID: 27921090.

15 Wirleitner B, Schuff M, Vanderzwalmen P, Stecher A, Okhowat J, Hradecký L, Kohoutek T, Králícková M, Spitzer D and Zech $\mathrm{NH}$ : Intrauterine administration of human chorionic gonadotropin does not improve pregnancy and life birth rates independently of blastocyst quality: a randomised prospective study. Reprod Biol Endocrinol 13: 70, 2015. PMID: 26141379. DOI: $10.1186 / \mathrm{s} 12958-015-0069-1$

16 Craciunas L, Tsampras N, Raine-Fenning N and Coomarasamy A: Intrauterine administration of human chorionic gonadotropin 
(hCG) for subfertile women undergoing assisted reproduction Cochrane Database Syst Rev 10: CD011537, 2018. PMID: 30341915. DOI: 10.1002/14651858.CD011537.pub3

17 Osman A, Pundir J, Elsherbini M, Dave S, El-Toukhy T and Khalaf Y: The effect of intrauterine HCG injection on IVF outcome: a systematic review and meta-analysis. Reprod Biomed Online 33: 350-359, 2016. PMID: 27317131. DOI: 10.1016/j.rbmo.2016.05.010

$18 \mathrm{Ye} \mathrm{H}, \mathrm{Hu} \mathrm{J}, \mathrm{He}$ W, Zhang Y and Li C: The efficacy of intrauterine injection of human chorionic gonadotropin before embryo transfer in assisted reproductive cycles: Meta-analysis. J Int Med Res 43: 738-746, 2015. PMID: 26359294. DOI: $10.1177 / 0300060515592903$

19 Aaleyasin A, Aghahosseini M, Rashidi M, Safdarian L, Sarvi F, Najmi Z, Mobasseri A and Amoozgar B: In vitro fertilization outcome following embryo transfer with or without preinstillation of human chorionic gonadotropin into the uterine cavity: A randomized controlled trial. Gynecol Obstet Invest 79: 201-205, 2014. PMID: 25531413. DOI: 10.1159/000363235

20 Cambiaghi AS, Leao RBF, Alvarez AV and Nascimento PF: Intrauterine injection of human chorionic gonadotropin before embryo transfer may improve clinical pregnancy and implantation rates in blastocysts transfers. Fertil Steril 100: S121, 2013. DOI: 10.1016/j.fertnstert.2013.07.1634

21 Eskandar M, Al-Emain M, Atwan Y and Bakar S: Does intrauterine injection of human chorionic gonadotropin before embryo transfer improve the pregnancy rate in in vitro fertilization/intracytoplasmic sperm injection (IVFICSI) cycles? A prospective randomized controlled trial. Reprod Sci 23(1_suppl): Abstr. No O-160, 2016. DOI: $10.1177 / 1933719116641257$

22 Hafezi M, Madani T, Arabipoor A, Zolfaghari Z, Sadeghi M and Ramezanali F: The effect of intrauterine human chorionic gonadotropin flushing on live birth rate after vitrified-warmed embryo transfer in programmed cycles: a randomized clinical trial. Arch Gynecol Obstet 297: 1571-1576, 2018. PMID: 29626233. DOI: 10.1007/s00404-018-4752-2

23 Hosseini RS, Farzadi L, Abdollahi S, Nouri M, Ghasemzadeh A, Hamdi $\mathrm{K}$ and Soleimanpour $\mathrm{H}$ : Effect of intrauterine injection of human chorionic gonadotropin before frozen-thawed embryo transfer on implantation and clinical pregnancy rate: a randomized controlled trial. In: International Journal of Women's Health and Reproduction Sciences. pp. 189-193, 2016. DOI: 10.15296/ijwhr.2016.42

24 Kokkali G, Chronopoulou M, Baxevani E, Biba M, Angeli I, Fakiridou M, Katouna A, Markomichali C, Petroutsou K and Vaxevanoglou T: A randomised control pilot study of the use of intrauterine human chorionic gonadotropin injection before embryo transfer in egg recipient cycles. Oxford Univ Press, Oxford, England, pp. 208-208, 2014.

25 Leao RBF, Cambiaghi AS, Leao BF, Alvarez PN and Figueiredo PN: Intrauterine injection of human chorionic gonadotropin before embryo transfer may improve the pregnancy rates in in vitro fertilization cycles of patients with repeated implantation failures. Proceedings of the 5th IVI International Congress, Seville, Spain, 2013. Available from: http://www.comtecmed.com/ivi/2013/ Uploads/Editor/abstract_66.pdf

26 Navali N, Gassemzadeh A, Farzadi L, Abdollahi S, Nouri M, Hamdi K, Mallah F and Jalilvand F: Intrauterine administration of hCG immediately after oocyte retrieval and the outcome of ICSI: a randomized controlled trial. Hum Reprod 31: 2520-2526, 2016. PMID: 27680029. DOI: 10.1093/humrep/dew236
27 Singh R and Singh M: Intra-uterine administration of human chorionic gonadotrophin (hCG) before embryo transfer in recurrent implantation failure (RIF) patients improves implantation and pregnancy rates in IVF-ICSI cycles. Oxford Univ Press, Oxford, England, pp. 79-80, 2014. DOI: 10.1093/humrep/29.Supplement_1.1

28 Zarei A, Parsanezhad ME, Younesi M, Alborzi S, Zolghadri J, Samsami A, Amooee $S$ and Aramesh $S$ : Intrauterine administration of recombinant human chorionic gonadotropin before embryo transfer on outcome of in vitro fertilization/ intracytoplasmic sperm injection: A randomized clinical trial. Iran J Reprod Med 12: 1-6, 2014. PMID: 24799855.

29 Craciunas L, Tsampras N, Coomarasamy A and Raine-Fenning $\mathrm{N}$ : Intrauterine administration of human chorionic gonadotropin (hCG) for subfertile women undergoing assisted reproduction. Cochrane Database Syst Rev: CD011537, 2016. PMID: 27195724. DOI: $10.1002 / 14651858$

30 Dehghani Firouzabadi R, Janati S, Mohseni F and Razi M: Evaluation effect of intrauterine human chorionic gonadotropin injection before embryo transfer in implantation and pregnancy rate in infertile patients and comparison with conventional embryo transfer in IVF/ICSI/ET cycles. Iran J Reprod Med $12(6$ Suppl 1): 70, 2014.

31 Nastri CO and Martins WP: EP28.06: Ultrasound guidance during embryo transfer: a systematic review and meta-analysis of randomised controlled trials. Ultrasound Obstet Gynecol 48: 383-383, 2016. PMID: 25052773. DOI: 10.1002/uog.14639

32 Martins WP, Nastri CO, Rienzi L, van der Poel SZ, Gracia C and Racowsky C: Blastocyst vs cleavage-stage embryo transfer: systematic review and meta-analysis of reproductive outcomes. Ultrasound Obstet Gynecol 49: 583-591, 2017. PMID: 27731533. DOI: $10.1002 /$ uog.17327

33 Braakhekke M, Kamphuis EI, Dancet EA, Mol F, van der Veen $\mathrm{F}$ and Mol BW: Ongoing pregnancy qualifies best as the primary outcome measure of choice in trials in reproductive medicine: an opinion paper. Fertil Steril 101: 1203-1204, 2014. PMID: 24786739. DOI: 10.1016/j.fertnstert.2014.03.047

34 Barnhart KT: Live Birth is the Correct outcome for clinical trials evaluating therapy for the infertile couple. Fertil Steril 101: 1205-1208, 2014. PMID: 24786740. DOI: 10.1016/j.fertnstert. 2014.03.026

35 Niederberger C, Pellicer A, Cohen J, Gardner DK, Palermo GD, O'Neill CL, Chow S, Rosenwaks Z, Cobo A, Swain JE, Schoolcraft WB, Frydman R, Bishop LA, Aharon D, Gordon C, New E, Decherney A, Tan SL, Paulson RJ, Goldfarb JM, Brännström M, Donnez J, Silber S, Dolmans M-M, Simpson JL, Handyside AH, Munné S, Eguizabal C, Montserrat N, Izpisua Belmonte JC, Trounson A, Simon C, Tulandi T, Giudice LC, Norman RJ, Hsueh AJ, Sun Y, Laufer N, Kochman R, Eldar-Geva T, Lunenfeld B, Ezcurra D, D'Hooghe T, Fauser BCJM, Tarlatzis BC, Meldrum DR, Casper RF, Fatemi HM, Devroey P, Galliano D, Wikland M, Sigman M, Schoor RA, Goldstein M, Lipshultz LI, Schlegel PN, Hussein A, Oates RD, Brannigan RE, Ross HE, Pennings G, Klock SC, Brown S, Van Steirteghem A, Rebar RW and LaBarbera AR: Forty years of IVF. Fertil Steril 110: 185324.e5, 2018. PMID: 30053940. DOI: 10.1016/j.fertnstert. 2018.06.005

36 McRae C, Sharma V and Fisher J: Metabolite profiling in the pursuit of biomarkers for IVF outcome: The case for metabolomics studies. Int J Reprod Med 2013, 2013. PMID: 25763388. DOI: $10.1155 / 2013 / 603167$ 
37 Barash A: Local injury to the endometrium doubles the incidence of successful pregnancies in patients undergoing in vitro fertilization. Fertil Steril 79: 1317-1322, 2003. PMID: 12798877. DOI: $10.1016 / \mathrm{s} 0015-0282(03) 00345-5$

38 Cervelló I, Santamaría X, Miyazaki K, Maruyama T and Simón C: Cell Therapy and Tissue Engineering from and toward the Uterus. Semin Reprod Med 33: 366-372, 2015. PMID: 26285168. DOI: $10.1055 / \mathrm{s}-0035-1559581$

39 Li S, Wang J, Cheng Y, Zhou D, Yin T, Xu W, Yu N and Yang J: Intrauterine administration of hCG-activated autologous human peripheral blood mononuclear cells (PBMC) promotes live birth rates in frozen/thawed embryo transfer cycles of patients with repeated implantation failure. J Reprod Immunol 119: 15-22, 2017. PMID: 27915038. DOI: 10.1016/j.jri.2016.11.006

40 Sfakianoudis K, Simopoulou M, Nitsos N, Rapani A, Pantou A, Vaxevanoglou T, Kokkali G, Koutsilieris M and Pantos K: A case series on platelet-rich plasma revolutionary management of poor responder patients. Gynecol Obstet Invest: 1-8, 2018 PMID: 30134239. DOI: 10.1159/000491697

41 Zadehmodarres S, Salehpour S, Saharkhiz N and Nazari L: Treatment of thin endometrium with autologous platelet-rich plasma: a pilot study. JBRA Assist Reprod 21, 2017. PMID: 28333034. DOI: 10.5935/1518-0557.20170013

42 Loke YJ and Craig JM: Are the effects of IVF on DNA methylation driven by intracytoplasmic sperm injection and male infertility? Epigenomics 8: 881-884, 2016. PMID: 27366826. DOI: $10.2217 /$ epi-2016-0041

43 Harper J, Cristina Magli M, Lundin K, Barratt CLR and Brison D: When and how should new technology be introduced into the IVF laboratory? Hum Reprod 27: 303-313, 2012. PMID: 22166806. DOI: 10.1093/humrep/der414

44 Licht P: Novel insights into human endometrial paracrinology and embryo-maternal communication by intrauterine microdialysis. Hum Reprod Update 4: 532-538, 1998. PMID: 10027606. DOI: $10.1093 /$ humupd/4.5.532

45 Paiva P, Hannan NJ, Hincks C, Meehan KL, Pruysers E, Dimitriadis E and Salamonsen LA: Human chorionic gonadotrophin regulates FGF2 and other cytokines produced by human endometrial epithelial cells, providing a mechanism for enhancing endometrial receptivity. Hum Reprod Oxf Engl 26: 1153-1162, 2011. PMID: 21345913. DOI: 10.1093/humrep/der027
46 Ye H, Zheng T, Li W, Li X, Fu X, Huang Y, Hu C, Li J, Huang J, Liu Z, Zheng L and Zheng Y: Ovarian Stem Cell Nests in Reproduction and Ovarian Aging. Cell Physiol Biochem 43: 1917-1925, 2017. PMID: 29055950. DOI: 10.1159/000484114

47 Jurisicova A, Antenos M, Kapasi K, Meriano J and Casper RF: Variability in the expression of trophectodermal markers betahuman chorionic gonadotrophin, human leukocyte antigen-G and pregnancy specific beta- 1 glycoprotein by the human blastocyst. Hum Reprod Oxf Engl 14: 1852-1858, 1999. PMID: 10402404. DOI: $10.1093 /$ humrep/14.7.1852

48 Lopata A and Hay DL: The potential of early human embryos to form blastocysts, hatch from their zona and secrete HCG in culture. Hum Reprod Oxf Engl 4: 87-94, 1989. PMID: 2613878. DOI: $10.1093 /$ humrep/4.suppl_1.87

49 Makrigiannakis A, Vrekoussis T, Zoumakis E, Kalantaridou SN and Jeschke U: The role of HCG in implantation: A mini-review of molecular and clinical evidence. Int J Mol Sci 18, 2017. PMID: 28629172. DOI: 10.3390/ijms 18061305

50 Nwabuobi C, Arlier S, Schatz F, Guzeloglu-Kayisli O, Lockwood CJ and Kayisli UA: hCG: Biological functions and clinical applications. Int J Mol Sci 18, 2017. PMID: 28937611. DOI: $10.3390 / \mathrm{ijms} 18102037$

51 Lu S, Peng H, Zhang H, Zhang L, Cao Q, Li R, Zhang Y, Yan L, Duan E and Qiao J: Excessive intrauterine fluid cause aberrant implantation and pregnancy outcome in mice. PLOS ONE 8, 2013. PMID: 24194934. DOI: 10.1371/journal.pone.0078446

52 Marconi G, Vilela M, Belló J, Diradourián M, Quintana R and Sueldo C: Endometrial lesions caused by catheters used for embryo transfers: a preliminary report. Fertil Steril 80: 363-367, 2003. PMID: 12909500. DOI: 10.1016/s0015-0282(03)00607-1

Received June 19, 2019

Revised September 4, 2019

Accepted September 6, 2019 